SECTION 31. Economic research, finance, innovation.

Kovalenko Gennady Vasilyevich Associate Professor, Ph.D., St.Petersburg State Polytechnical University, Russia e-mail: 7525268@gmail.com

Kolosova Olga Vladimirovna Professor, D.Sc., St.Petersburg State Polytechnical University, Russia e-mail: kolosova@yandex.ru

\title{
INNOVATION PROJECTS MANAGERS PERCEPTION AND ASSESSMENT OF RISKS
}

\begin{abstract}
The problem of the innovative projects managers' perception of risk is discussed. The results of innovation projects' risks assessment by their managers compared with the estimate given by small business entrepreneurs to their projects are analyzed. The underestimation of market risks by the leaders of innovative projects including consumers' solvency, competition and price volatility is presented. The causes of discrepancies between theoretical assumptions about the high riskiness of innovative projects and its evaluation by managers in practice are debated.
\end{abstract}

Key words: innovation, project, risk, risk perception, risk assessment, project managers.

\section{УДК 65.013:330.131.7:303.823.3}

\section{ВОСПРИЯТИЕ И ОЦЕНКА РИСКА МЕНЕДЖЕРАМИ ИННОВАЦИОННЫХ ПРОЕКТОВ}

\begin{abstract}
Аннотация: Обсуждается проблема восприятия риска менеджерами инновационных проектов. Анализируются результаты исследования оценки рискованности инновационных проектов их руководителями в сопоставлении с оценкой, даваемой своим проектам предпринимателями малого бизнеса. Показывается недооиенка руководителями инновационных проектов рыночных рисков платежеспособности потребителей, конкуренции, ценовой нестабильности. Дискутируются причины расхождения между теоретическими положениями о высокой рискованности инновационных проектов и ее оценками менеджерами на практике.
\end{abstract}

Ключевые слова: инноваџии, проект, риск, восприятие риска, оценка риска, менеджеры проектов.

Считается, что XXI век - это век, в котором человеческое общество перешло на принципиально иную ступень в своем развитии, оно стало «обществом риска» [1]. Не случайно в развитых экономически странах столь велик интерес к такому направлению деятельности как управление рисками или риск-менеджмент. В России это направление только развивается, наглядным примером чему служат действующие российские стандарты по риск-менеджменту, являющиеся, как правило, переводами международных стандартов.

Предпринимательство, инновации, инициатива - все эти понятия объединяет одна общая черта - они неразрывно связаны с риском. Умение менеджера работать с рисками становится более чем приоритетным в обширном списке задач, возникающих при подготовке менеджеров [2]. Не измерив количественно отношение менеджеров, инноваторов и предпринимателей к риску и управлению им, сложно без конкретных 
ориентиров проводить эффективную работу по поддержанию и развитию культуры управления рисками и риск-менеджерских компетенций у предприимчивых людей, желающих работать в сфере инноваций. К сожалению, подобные количественные измерения в нашей стране практически отсутствуют, лишь в 2013 году впервые в России Ассоциацией молодых предпринимателей России (АМПР) было проведено исследование отношения к рискам и управлению ими 1700 молодых отечественных предпринимателей [3], которое показало недостаточный уровень компетенций предпринимателей в области управления рисками.

Авторы статьи в целях повышения качества обучения участников Президентской программы подготовки управленческих кадров по программам «Руководители инновационных проектов» и «Менеджмент инноваций» провели собственное мини-исследование представлений слушателей об управлении рисками проектов, их мнений о рисках разрабатываемых ими инновационных проектов, направлениях развития возможных проблемных ситуаций и управления проектными рисками. Оно представляется актуальным в свете 62-го места из 142, занятого Россией в 2013 году, по версии The Global Innovation Index [4, с. 10] и нулевого уровня развития информационной инфраструктуры риск-менеджмента, как значимого фактора конкурентоспособности страны [5, с.123]. Методика исследования - анкетирование, проведенное в январе 2014 года, и выстроенное, в целях обеспечения сравнимости и сопоставимости результатов, по аналогии с исследованием АМПР, но с уточненным перечнем вопросов и формулировками применительно к специфике целевой фокусгруппы. В эту группу входили слушатели Президентской программы (далее по тексту инноваторы), имеющие уже за плечами как минимум трехлетний опыт руководства инновационными проектами и четыре месяца обучения на ней.

По результатам обработки анкет оказалось, что более половине инноваторов (далее по тексту таблиц обозначаются как «И») известно, что такое управление рисками проектов, при этом 13\% хорошо владеют данной тематикой (табл.1). При этом также больше половины, а именно 54\%, хотели бы расширить свои знания в этой области. Иными словами, научиться более эффективно рационализировать свои страхи и опасения.

Таблица 1

Осведомленность об управлении рисками

\begin{tabular}{|l|c|}
\hline Слышал раньше & $43 \%$ \\
\hline Хорошо знаком & $13 \%$ \\
\hline Слышу первый раз & $0 \%$ \\
\hline
\end{tabular}

Судя по ответам, имеющиеся у инноваторов знания в области управления рисками позволяют им более эффективно, по крайней мере, на первый взгляд, не допускать превращения рисков в проблемы (табл.2). Так утверждают почти 90\% инноваторов, по сравнению с 60\% молодых предпринимателей (далее по тексту таблиц - П). Разница существенная, скорее всего объясняется она уже наличествующим высоким уровнем менеджерских компетенций слушателей, проходящих профессиональную переподготовку, а также характеризующейся более высокими рисками спецификой инновационной деятельности.

Таблица 2

Заблаговременность решения проблем

\begin{tabular}{|l|c|c|}
\hline & И & П \\
\hline Решаю потенциальные проблемы заблаговременно & $89 \%$ & $60 \%$ \\
\hline Решаю проблемы по мере поступления & $11 \%$ & $40 \%$ \\
\hline
\end{tabular}


Соответственно, логичной далее выглядит ситуация, что большинство инноваторов показывают, что неожиданности их редко застают врасплох. Готовность инноваторов встретить неожиданности существенно выше, чем у предпринимателей (табл. 3).

Таблица 3

Неожиданности врасплох

\begin{tabular}{|l|c|c|}
\hline & И & П \\
\hline Редко & $56 \%$ & $35 \%$ \\
\hline Я заблаговременно готов к неожиданностям & $28 \%$ & $5 \%$ \\
\hline Часто & $13 \%$ & $55 \%$ \\
\hline
\end{tabular}

Среди ключевых направлений риск-деятельности, что у предпринимателей, что у инноваторов, совпадающе актуальным является анализ рисков при выходе на новые рынки сбыта (табл. 4). Что касается эффективного реагирования на действия конкурентов, то вполне логичным выглядит относительно низкий приоритет этой деятельности у инноваторов, в сравнении с предпринимателями. Действительно инновационный проект позволяет его инициатору не опасаться конкуренции, поскольку они опережают потенциальных конкурентов, а на сложившихся рынках, где действуют предприниматели, риски конкуренции, более чем актуальны. Хотя вполне возможно, что зачастую инноваторы недооценивают способность российского рынка порождать конкурентов, в том числе имитаторов из серии «все тоже самое, но на рубль дешевле». Кроме того, видимо, недооценивается роль бизнес-модели инновационного проекта в его конечном успехе или неудаче. Выход на первое место деятельности по снижению операционных потерь у инноваторов, по сравнению с предпринимателями, может быть объяснена несколькими версиями, в том числе тем, что инноваторы, имея возможность не обращать внимание на конкурентов, могут позволить себе сосредоточится на снижении текущих затрат, делая более инвестиционно привлекательными свои проекты. Вполне понятным и логичным является и отсутствие интереса у инноваторов к такому способу обработки рисков, как страхование, в сравнении с необходимостью снижения затрат на его применение у предпринимателей.

Таблица 4

Актуальность риск-направлений

\begin{tabular}{|l|c|c|}
\hline & И & П \\
\hline Снижение операционных потерь & $44 \%$ & $31 \%$ \\
\hline Анализ рисков при выходе на новые рынки сбыта & $43 \%$ & $36 \%$ \\
\hline Улучшение условий финансирования & $28 \%$ & $25 \%$ \\
\hline Эффективное реагирование на действия конкурентов & $26 \%$ & $46 \%$ \\
\hline Другое & $20 \%$ & нет \\
\hline Снижение страховых премий & $0 \%$ & $19 \%$ \\
\hline
\end{tabular}

В очередной раз подтвердилась древняя как сам мир сентенция, что «кадры решают все». На первое место по степени внимания, что инноваторами, что предпринимателями поставлены люди. Вполне ожидаемо для рыночных условий деловой активности, что на втором месте, и у тех, и у других стоят продажи. Слабая восприимчивость отечественной производственной базы к инновациям явно прослеживается в том, что по степени подверженности рискам сфера производства располагается у инноваторов на третьем месте. При этом, есть ощущение, что сконцентрировавшись на своей инновационной идее, инноваторы недооценивают 
риски закупочной деятельности, бухгалтерского и налогового учета, которые в условиях отечественной экономики возникнут гарантированно (табл. 5).

Таблица 5

Подверженность рискам

\begin{tabular}{|l|c|c|}
\hline & И & П \\
\hline Кадры & $48 \%$ & $39 \%$ \\
\hline Продажи & $37 \%$ & $35 \%$ \\
\hline Производство & $26 \%$ & $15 \%$ \\
\hline Транспортировка и логистика & $20 \%$ & $16 \%$ \\
\hline ИТ системы & $13 \%$ & $12 \%$ \\
\hline Закупки & $11 \%$ & $21 \%$ \\
\hline Безопасность & $11 \%$ & $19 \%$ \\
\hline Бухгалтерский и налоговый учет & $2 \%$ & $35 \%$ \\
\hline Другое & $2 \%$ & $6 \%$ \\
\hline
\end{tabular}

В оценке значимости групп рисков (по пятибалльной шкале) обе наши выборки проявили практически полное единодушие - это группы рисков, связанные с кадрами, и внешними рисками, к которым в полной мере можно отнести финансовые и государственные риски (табл. 6). Судя по всему, в этом отношении в значительной степени проявляют себя неустойчивость национальной валюты отечественной экономики и 92-е место России в рейтинге Doing Business-2014 [6, с. 3].

Таблица 6

\section{Значимость групп рисков}

\begin{tabular}{|l|c|c|}
\hline \multicolumn{1}{|l|}{} & И & П \\
\hline $\begin{array}{l}\text { Риски персонала - нехватка персонала, зависимость от ключевых } \\
\text { сотрудников, мошенничество, недостаток квалификации }\end{array}$ & 3,91 & 3,10 \\
\hline $\begin{array}{l}\text { Внешние риски - действия конкурентов, изменение спроса, } \\
\text { финансовый кризис }\end{array}$ & 3,37 & 3,80 \\
\hline $\begin{array}{l}\text { Государственные риски - изменение законодательства, проверки, } \\
\text { коррупция }\end{array}$ & 3,31 & 2,50 \\
\hline Финансовые риски - налоговые, валютные, процентные & 2,87 & 3,80 \\
\hline Произвдственные риски - рост цен на сырье, износ оборудования & 2,57 & 3,40 \\
\hline Риски безопасности - ИТ атаки, хищения, охрана труда & 2,37 & 1,50 \\
\hline
\end{tabular}

Данные, приведенные в табл.7, подтверждают ранее сделанные обобщения. В отличие от предпринимателей инноваторы не считают опасной для своего проекта конкуренцию, а также в большей степени уверены в платежеспособности своих клиентов, чем действующие предприниматели, но, как и последние, опасаются снижения спроса на свою продукцию (работы, услуги). По понятным причинам у инноваторов, на втором месте по степени опасений стоят «административные барьеры и избыточная бюрократия», в то время как на аналогичной позиции у предпринимателей - опасения по поводу «агрессивной ценовой политики существующих конкурентов». Изменения законодательства и частые и необоснованные проверки государственных органов вызывают одинаковое беспокойство как у инноваторов, так и у предпринимателей. При этом больше внимания инноваторы уделяют таким рискам, как низкое качество бизнес-планирования, устаревшие технологии и износ оборудования, что естественным образом следует из инновационного характера направленности их проектов. 
Таблица 7

Нежелательность рисков

\begin{tabular}{|c|c|c|}
\hline & И & $\Pi$ \\
\hline Низкая квалификация персонала или нехватка компетенций & $48 \%$ & $35 \%$ \\
\hline Административные барьеры и избыточная бюрократия & $44 \%$ & $14 \%$ \\
\hline Снижение спроса на продукт проекта & $33 \%$ & $33 \%$ \\
\hline Низкое качество бизнес-планирования & $28 \%$ & $17 \%$ \\
\hline Неплатежеспособность потребителей продукта проекта & $28 \%$ & $38 \%$ \\
\hline Новые конкуренты на рынке & $24 \%$ & $64 \%$ \\
\hline Устаревшие технологии & $24 \%$ & $14 \%$ \\
\hline Изменение законодательства & $24 \%$ & $19 \%$ \\
\hline Частые и необоснованные проверки гос. органов & $19 \%$ & $22 \%$ \\
\hline Агрессивная ценовая политика существующих конкурентов & $15 \%$ & $39 \%$ \\
\hline Износ оборудования & $13 \%$ & $12 \%$ \\
\hline "Черный пиар" со стороны конкурентов & $13 \%$ & $31 \%$ \\
\hline $\begin{array}{l}\text { Риски непрерывности (отсутствие аварийного запаса, альтернативных } \\
\text { каналов закупок и продаж) }\end{array}$ & $13 \%$ & $20 \%$ \\
\hline Мошенничество со стороны персонала & $13 \%$ & $18 \%$ \\
\hline Изменение цен на сырье или закупаемое оборудование & $11 \%$ & $29 \%$ \\
\hline Невозможность привлечь финансирование на доступных условиях & $11 \%$ & $8 \%$ \\
\hline Налоговые или правовые риски & $11 \%$ & $23 \%$ \\
\hline Потеря ключевого поставщика & $6 \%$ & $26 \%$ \\
\hline Колебания валютных курсов & $6 \%$ & $14 \%$ \\
\hline $\begin{array}{l}\text { Изменение процентных } \\
\text { финансированию }\end{array}$ & $6 \%$ & $4 \%$ \\
\hline Атаки на ИТ системы & $6 \%$ & $7 \%$ \\
\hline Низкий уровень охраны труда & $6 \%$ & $4 \%$ \\
\hline Хищения или кражи & $6 \%$ & $13 \%$ \\
\hline $\begin{array}{l}\text { Неконкурентоспособность продукта проекта на рынке в связи с } \\
\text { вступлением России в ВТО }\end{array}$ & $6 \%$ & $3 \%$ \\
\hline Другое & $6 \%$ & $1 \%$ \\
\hline
\end{tabular}

Несколько неожиданными оказались результаты оценки инноваторами степени подверженности своих проектов рискам. В представлении инноваторов развиваемые ими проекты не подвержены высокому риску (табл. 8), а 2\% вообще ответило, что рисков в проекте нет.

Таблица 8

Подверженность проектов риску

\begin{tabular}{|l|c|c|}
\hline & И & П \\
\hline Высокая подверженность риску & $9 \%$ & $32 \%$ \\
\hline Средняя подверженность риску & $44 \%$ & $47 \%$ \\
\hline Низкая подверженность риску & $44 \%$ & $21 \%$ \\
\hline Проект, в которой отсутствуют какие-либо риски & $2 \%$ & нет \\
\hline
\end{tabular}

Такое представление входит в принципиальное противоречие с самим характером понятия инновационность, которое априори подразумевает высокую рискованность инновационных проектов, тем более в условиях экономики, слабо восприимчивой к новациям. Противоречие можно объяснить, тем что, либо 
разрабатываемые инноваторами проекты на самом деле не относятся в полной мере к инновационным и разработчики, по крайней мере, на уровне подсознания это осознают, либо инноваторы не представляют себе реальную рискованность своих проектов. Последнее, как феномен «overconfidence», подробно описан в [7, с. 29]. Нечто похожее, правда, относящееся к лизингу, было замечено в ходе анализа результатов сертификации специалистов по лизингу $[8,9]$. Применительно к нашему случаю, противоречие, скорее всего, объясняется тем, разрабатываемые инноваторами проекты не несут значимых рисков лично для них, они не являются собственниками риска, за них рискует кто-то другой. Также велика вероятность высокой приверженности слушателей своим идеям и глубокой вовлеченности в процесс их продвижения, что естественным образом снижает представление о предстоящих рисках. Такая форма реализации человеческого фактора отмечалась в [10].

Таким образом, результаты исследования показали хорошее знакомство инноваторов с управлением рисками и желание дальше развивать свои компетенции в этой сфере. Инноваторы, по их мнению, уверенно представляют структуру рисков своих инновационных проектов, при этом, скорее всего, недооценивая риски закупочной деятельности, бухгалтерского и налогового учета. Они не испытывают особого беспокойства по поводу платежеспособности своих будущих клиентов и считают, что реализация проектов не встретит особого конкурентного противодействия. Все это, возможно, приводит их к мысли, что их инновационные проекты не являются в принципе рискованными, ведь лично им неуспех проекта в ряде случаев ничем существенным не грозит.

\section{Литература}

1. Beck, U. World at Risk. - Cambridge: Polity Press, 2009. - 240 p.

2. Зинов В.Г., Кабанов В.А., Колосова О.В., Расковалов В.Л., Туккель И.Л. Задачи кадрового обеспечения инновационной деятельности // Научно-технические ведомости СПбГПУ. Наука и образование (инноватика). 2009. № 5(87). С. 180-187.

3. Комитет по управлению рисками Ассоциации молодых предпринимателей России провел исследование по основным проблемам бизнес-сферы среди 1700 предпринимателей из разных регионов страны 24.04.2013. - Режим доступа: www.moldelo.ru

4. The Global Innovation Index 2013: The Local Dynamics of Innovation. Geneva: Cornell University, INSEAD, and WIPO, 2013. - 392 p.

5. Kovalenko G.V. Consideration of the level of information infrastructure development of the risk-management in the country as the factor of global competitiveness of its economy // Theoretical\&Applied Science. 2014. № 1 (9). P.121-124.

6. Doing Business 2014: Understanding Regulations for Small and Medium-Size Enterprises. - Washington, DC: World Bank Group, 2013. -306 p.

7. Virine, L., Trumper, M. ProjectThink: Why Good Managers Make Poor Project Choices. - Surrey: Gower, 2013. - 252 p.

8. Коваленко Г.В. О трендах в сертификации специалистов по лизингу // Лизинг. 2010. № 8. С. 38-40.

9. Коваленко Г.В. Сертификация специалистов по лизингу: состояние и перспективы // Лизинг. 2010. № 1. С. 50-52.

10. Колосова О.В., Леонова О.В. Управление изменениями в организациях на базе процессного подхода с учетом человеческого фактора // Научно-технические ведомости СПбГПУ. 2011. №3 (121). С. 81-86. 